\title{
Tumor Banks: The Cornerstone of Basic Research in Urology
}

\author{
Sabrina T. Reis, Emanoela B. Feitosa, Jose Pontes-Junior, Camila C. Marin, Daniel K. Abe, \\ Alexandre Crippa, Alberto A. Antunes, Adriano J. Nesrallah, Luiz C. Oliveira, Leopoldo A. \\ Ribeiro-Filho, Miguel Srougi, Katia R. M. Leite, Marcos F. Dall'Oglio
}

Laboratory of Medical Investigation (STR, JPJ, KRML), Division Urology (EBF, JPJ, CCM, DKA, AC, AAA, AJN, LCO, LARF, MS, MFDO), School of Medicine, University of Sao Paulo, Sao Paulo, Brazil

\begin{abstract}
Purpose: Tumor banks have the primary responsibility for collecting, cataloging, storing and disseminating samples of tissues, cells and fluids, which are used by researchers to identify diagnostic molecular markers, prognostic indicators and therapeutic targets. The objective of this review was to describe a simple, reliable and reproducible protocol for obtaining and storing samples of urological tumors.

Materials and Methods: Urogenital tumor tissues were collected by the surgeons from the Urology Division of University of Sao Paulo Medical School. The obtained surgical specimens were immediately placed in liquid nitrogen, dry ice or in a tube containing RNAlater ${ }^{\circledR}$, and then stored by cryopreservation $\left(-80^{\circ} \mathrm{C}\right)$. A mirror fragment was fixed in $10 \%$ formalin processed routinely and embedded in Paraplast ${ }^{\circledR}$.

Results: We developed a protocol for the collection, cataloging, storage, conservation and use of tumor samples. During a period of one year the Urological Tumor Bank of the Urology Division stored 274 samples of prostate, bladder, kidney, penis and testicle tumors of different histological types, 74 urine and 271 serum samples.

Conclusions: Having biological materials characterized and available along with the clinical patient information provides an integrated portrait of the patients and their diseases facilitating advances in molecular biology. It also promotes the development of translational research improving methods of diagnosis and cancer treatment.
\end{abstract}

Key words: biological specimen banks; urogenital neoplasms; tissue banks; pathology; molecular biology

Int Braz J Urol. 2010; 36: 348-54

\section{INTRODUCTION}

According to the Council of Europe, (1997), in Commentary 137 to article 22, "a tumor bank is an organization responsible for collecting, cataloging, storing and disseminating samples of tissues, cells and fluids for the investigation of diagnostic molecular markers, definition of prognosis and identification of therapeutic targets (1), for facilitating the discovery of new therapies and new drugs, and for other applications yet to be discovered" (2).

All organs of the urogenital tract are potential targets of malignant tumors, and although prostate cancer has the higher incidence, there is a need for the study of tumors of the bladder, kidney, urethra, testicles and penis to help optimize methods to be applied in diagnosis, prognosis and treatment of these diseases. The tumor bank of the Urology Division at 
the University of Sao Paulo Medical School (USPMS) was established in 2008 and differs from the other banks by storing only samples of urological tumors, in order to increase the number of basic studies and clinical research.

Brazil has three major banks that store tumor specimens of various types of cancer: the Barretos Cancer Hospital has 19,000 samples, AC Camargo Cancer Hospital has 13,000 samples and the National Cancer Institute has 7,000 samples.

The objective of this review was to describe a simple, reliable and reproducible protocol for obtaining and storing samples of urological tumors; to clarify basic concepts related to tumor banks, their organization, relevance, quality and ethics; and to describe the tumors in the bank created by the Urology Division of USPMS.

Two principles are fundamental for good basic and clinical research: the accuracy of clinical information and outcome of patients treated by cancer and the quality of tumor samples that will allow the search for molecular abnormalities involved with neoplastic development and progression. A tumor bank with an effective protocol allows researchers to store and access tumor tissue samples under ideal conditions for research and recovery of patient data (3). This systematic organization of information allows the development of cancer research with solid scientific conclusions (4).

According to Teodorovic et al. (5) tumor banks contribute to translational research by promoting more and better integration between clinicians and researchers. Translational research is an integration of clinical and laboratory research aiming the improvement of prevention, diagnosis and treatment of diseases via the practical application of scientific discoveries (5-7). The identification of a tumor or a biological marker allows a better understanding of the pathology, diagnosis, prognostic indicators, most appropriate therapy and the potential of recurrence. For example, prostate-specific antigen serves as a marker for prostatic cancer (5) and is used by urologists to better assess patients and to obtain greater precision in evaluating the diverse characteristics of the disease.

According to Alimena et al. (4), the idea of using a therapy that reaches only the neoplastic cells and the identification of markers capable of distinguishing sensitive patients from patients resistant to first-line therapy are both the result of the creation of tissue banks.

Pathologists and molecular biologists have been responsible for such studies, conducting laboratory research with the practical goal of not only contributing to clinical knowledge, but also guiding the clinician in the evaluation of patients (4). Chu et al. (8) described molecular biology as a discipline that uses the techniques available to study diseases and their implications.

The tumor bank of the Urology Division of USPMS was created with the goal of aiding a new line of research in urological oncology. Having these biological materials available and characterized, along with the clinical information of the patients, provides an integrated portrait of the patients and their illnesses, enabling advances in molecular biology. Tumor banks may be useful in the future because constant medical and technological advances in early diagnosis and pre-operative therapies will reduce the number of surgeries for tumor removal, thus jeopardizing the collection of tumor tissues. Therefore, a network of tumor banks must be organized to ensure appropriate and responsible use of the materials (9).

Informatics (10) can facilitate patient registration, specimen tracking, tissue cataloguing, quality assurance, and specimen availability. The ability of databases to organize and present desired information can also aid in tracking informed consent and institutional compliance and be could used to generate tissue bank inventory reports to match investigator requests with specimen availability.

The components of a system must be faultless in order to allow efficient data entry, queries and report preparation, and must also allow rapid deployment of new services. The Urology Division of USPMS has a computer software exclusively established for the function of its tumor bank and also an electronic file system that allows the professionals involved in research to gain access to all clinical and laboratory information from each patient.

Each country defines the rules it believes are necessary to protect its citizens. Few countries, including Iceland and Sweden, have a law specifically related to tumor banks. The majority have Research Ethics 
Table 1 - Procedure for storage of collected tissue.

\begin{tabular}{ll}
\hline Cryopreservation $\left(-80^{\circ} \mathrm{C}\right)$ & Embedding in Paraplast $^{\circledR}$ \\
\hline Benefits & Benefits \\
Morphological studies of high quality & Cheaper \\
Molecular, immunohistochemical and cytogenetic analyses & Half-life unlimited \\
Extraction of high quality DNA, RNA and protein & Histological morphology of high quality \\
Disadvantages & Disadvantages \\
Half-life: 1 decade or more & The genetic material may be damaged \\
More expensive and more difficult & \\
\hline
\end{tabular}

Committees (REC) that has to approve research that will use the samples of tumor banks, acting only once the tissue is stored but not for storage of samples.

Oosterhuis et al. (2) summarized the principles to which all tumor banks must comply: i) Protect the interests of donors; ii) Give patients full information about the project and appropriate research; iii) Uphold and ensure the balance between the interests of science and donors; iv) Prohibit the commercial use of human tissue.

In Brazil, the ethical issues related to research activities involving human beings are governed by the Guidelines and Standards for Research in Human Beings, introduced by Resolution 196/96 of the National Health Council (11). Resolution 347/05 regulates the storage and use of human biological material for research purposes (12).

According to Resolution 196/96, the respect due to human dignity requires that all research is conducted after free and informed consent of patients. The patient must sign a form to agree that their material can be included in the tumor bank, and when that material is part of a study approved by the tumor bank and the REC, the patient must be contacted and has to sign an additional form referring to the study that seeks the material. In cases where it is impossible to obtain the consent of the patient (e.g. death,), this fact must be documented with an explanation of the cause of failure and the opinion of the REC.

Resolution 347 states that the REC should be informed of the formation of a tumor bank and of its objectives and responsibilities.

\section{MATERIALS AND METHODS}

\section{Standard Operational Procedure of the Urological Tumor Bank}

Biological materials are stored by cryopreservation $\left(-80^{\circ} \mathrm{C}\right)$ and in paraffin blocks (Table-1). After surgical specimens are removed, the fresh tissue is immediately placed in liquid nitrogen, dry ice or in a tube containing RNAlater ${ }^{\circledR}$ (a solution that preserves the genetic material of the tissue for a longer period), which is then stored at $-80^{\circ} \mathrm{C}$. The freezer is localized in a special room designed for $-80^{\circ} \mathrm{C}$ freezers where freezer temperature is controlled $24 \mathrm{~h}$ by a computerized system MV2000 (Yokogawa). Additionally a generator is installed to supply the equipment in case of energy failure. The material is available only to accredited researchers in the Urology Division and is used after approval of the REC. A mirror fragment of the specimen frozen is fixed in $10 \%$ buffered formalin routinely processed and embedded in Paraplast ${ }^{\mathbb{B}}$. Central morphologic reviews are performed on the formalin-fixed samples, including assessment of tumor diagnosis, percent of tumor, stroma, and necrosis.

The physician responsible for the surgery is also responsible for the collection of the Consent Form and the tumor sample. Immediately after surgical removal, a fragment of the tumor is removed and put into a plastic tube resistant to low temperatures with RNAlater ${ }^{\circledR}$ and is immediately labeled with a code for identification. 
At the tumor bank of the Escola Paulista de Medicina / UNIFESP (4), as well as in our bank, the procedure is performed in the operating room with the patient anesthetized or under regional blockade. The collection neoplastic tissue samples are performed with a scalpel in the areas affected by the tumor. A preliminary assessment of the material is performed by direct palpation in areas more representative of the tumor. Then fragments are removed to provide material for pathological and genetic studies. The minimum size accepted for samples to be stored in a bank is $0.5 \times 0.5 \times 0.3 \mathrm{~cm}$. Completion of the identification data for the donor and the identification data for the sample of tissue is the sole responsibility of the technical team.

An important issue related to the collection of surgical specimens for tumor banking in urology is the histological verification process. This is necessary due the potential risk that no tumor is present in the collected fragments. It can occur in cases where the tumor volume is small or not able to be seen as in prostate cancer specimens. Therefore, before banking, the obtained tissue needs to be histologically verified to ascertain the presence of neoplasic cells. The mirror fragment fixed in formalin and embedded in Paraplast ${ }^{\circledR}$ is the better solution for this problem. But in cases where this procedure has not been done, before the experiments using the samples, a slide should be cut in a cryostat and stained in hematoxylin and eosin to verify the presence and amount of tumor represented in that specific tissue fragment.

Another important aspect is the precise site of fragment collection, especially for large tumors. A $10 \mathrm{~cm}$ kidney cancer may show histological and molecular heterogeneity when different parts of the tumor are examined. In bladder tumors, although the large amount of exophytic tumor appears homogeneous macroscopically, the bladder tumor base may be different at the molecular level. For this reason, our collecting protocol mandates that at least two different areas should be sampled for each case.

A nurse is responsible for collecting blood and urine, for labeling the samples and placing them in cold storage. A biologist is responsible for collecting all the material, processing the samples, cataloging them and storing them in a freezer at $80^{\circ} \mathrm{C}$.
If there is any problem with the tube used to store the tissue, it must be discarded and replaced. The samples should not remain more than 30 minutes without optimal storage conditions to prevent degradation of genetic material (DNA, RNA and proteins).

Another aspect that deserves mention is biosafety. Sastre-Garau (13) advised that the team involved must treat all materials as if they were contaminated, as there are risks inherent in handling biological samples, which could be infected by pathogens such as virus from human immunodeficiency and hepatitis B and C.

\section{Infrastructure}

There are minimum requirements for the operation of a tumor bank. A liquid nitrogen container or a $-80^{\circ} \mathrm{C}$ freezer is required for sample storage, and thus physical space for these systems is necessary. Space is also required for processing the samples, the freezing unit, RNAlater ${ }^{\circledR}$ later, media storage (boxes and tubes), computer equipment (computer and printer) and the team (physicians' surgeons, pathologists and nurse biologist). A continuous accounting system is essential in tumor banking to control the withdrawals and inclusion of samples at any time.

\section{Auditing}

An external audit is also necessary to ensure adequacy and quality control for any tumor bank. We acknowledge that the tumor bank must have a large numbers of samples sufficient for the completion and validation of any type of protocol but the most important aspect is the quality of the stored material, verified and complemented by ongoing clinical data accrual instead of sample size.

The establishment of a tumor bank in large hospitals has some advantages as a large and diverse population which is available at our Institution. Our tumor bank has been in existence for approximately one year and already has large numbers of samples that have been used in various studies involving urological neoplasms. 
Table 2-All material collected from the tumor bank of the Division of Clinical Urology, Oncology sector from August 2008 to June 2009.

\begin{tabular}{lc}
\hline Anatomical Location of the Tumor & Quantity \\
\hline Tumor samples & \\
Prostate & 130 \\
Bladder & 83 \\
Kidney & 51 \\
Penis & 03 \\
Testicle & 07 \\
Total & 274 \\
Serum & 271 \\
Urine & 74 \\
\hline
\end{tabular}

\section{RESULTS}

From August 2008 to June 2009 we collected 274 samples from different urogenital tumors as described in Table-2. There are also 74 urine and 271 serum samples that have been collected just before surgical procedure.

\section{COMMENTS}

Understanding cancer at the molecular level is a very important step for the identification of new markers for diagnosis and prognosis of cancer, representing a chance to create opportunities to develop target therapy. For this reason, it is of great importance to build a tumor collection in good storage conditions (2).

Urological tumors are a serious clinical problem, as they include high prevalence neoplasms such as prostate cancer and aggressive tumors such as kidney and bladder carcinomas. With the development of molecular biological techniques, the use of human neoplastic tissue is of great importance for cancer research. Therefore, we were prompted to begin development of protocols with extensive clinical and surgical data in order to create a tumor bank.

Regarding the storage of tumors, there are advantages and disadvantages to storing samples in a $-80^{\circ} \mathrm{C}$ freezer and freezing in liquid nitrogen. The benefits of the freezer are the ability to store about 15,000 $2 \mathrm{~mL}$ Eppendorf tubes, with easy access and less infrastructure requirement. The disadvantages are the high cost, the fragility of the equipment and its dependence on energy (4). To solve this problem there are liquid nitrogen backups that keeps the freezer at low temperature when lack of energy occurs, however only for a short period of time.

Storage in liquid nitrogen renders the access of the specimens difficult and requires constant maintenance of the level of nitrogen. The advantages are preservation at $-170^{\circ} \mathrm{C}$ and independence from energy (13). We chose to store the tumor bank in a $-80^{\circ} \mathrm{C}$ freezer. It is important to mention that freezers must be routinely checked to guarantee the constant temperature, crucial for the maintenance of integrity of surgical specimens, urine and serum. Also, a backup of gas supply or generator is imperative in case of electric energy failure. In our case we have a room in the main building of University of Sao Paulo Medical School specially designed for $-80^{\circ} \mathrm{C}$ freezers containing a computerized system for temperature control and generators.

It is imperative to record basic information from patients and their diseases to make a tumor bank useful for science. Gender, age, clinical and histopathological diagnoses, TNM classification, specification about a tumor as primary, metastatic or recurrent, occurrence of a previous treatment, type of sample, and most importantly the outcome of the patients should be recorded and be easily retrieved when necessary (14).

Finally, we must make clear that the benefits offered by research with human tumor or normal tissue from donors do not negate the serious and complex issues of medical-legal ethics. All information provided must be maintained in a way that guarantees donor anonymity. We also emphasize that the main goal of research must first be to afford some benefit to the patient and not to the researcher (8).

\section{CONCLUSION}

A tumor bank can be an instrument of great help for scientific research, as it offers tumor samples to researchers that have been stored under optimum 
conditions of preservation. Through analysis of these samples, the researcher can better understand the cancer regarding the diagnosis, prognosis, prophylaxis and treatment. A well-organized and structured tumor bank facilitates and enables basic research discoveries that can improve population health.

The disclosure of the protocol used by the urological tumor bank of the Urology Division of USPMS should assist other centers in training. Standardization of the handling of the specimens, collection and storage and having a link between tumor banks will also increase the quantity and scope of research through the exchange of samples. In addition, by comparing information from databases at different locations, the regional characteristics of tumors can be studied and related to the habits of the respective populations.

\section{CONFLICT OF INTEREST}

None declared.

\section{REFERENCES}

1. Hansson MO: Balancing the quality of consent. J Med Ethics. 1998; 24: 182-7.

2. Oosterhuis JW, Coebergh JW, van Veen EB: Tumour banks: well-guarded treasures in the interest of patients. Nat Rev Cancer. 2003; 3: 73-7.

3. Morente M: The CNIO Tumour Bank Network [Internet]. Spain: Centro Nacional de Investigaciones Oncológicas, c2000. [cited jan. 2009]. Available from: https://www.cnio.es/ing/grupos/plantillas/presentacion.asp?pag=529

4. Alimena LJM, Jesus-Garcia Filho R, Toledo SRC, Alves MTS, Petrilli AS, De Luca Junior G, et al: Protocolo de um banco de tecidos neoplásicos. Rev Bras Ortop. 2008; 43: 53-8.

5. Teodorovic I, Therasse P, Spatz A, Isabelle M, Oosterhuis W: Human tissue research: EORTC recommendations on its practical consequences. Eur J Cancer. 2003; 39: 2256-63.

6. Grizzle WE, Aamodt R, Clausen K, LiVolsi V, Pretlow TG, Qualman S: Providing human tissues for research: how to establish a program. Arch Pathol Lab Med. 1998; 122: 1065-76.

7. Barnes RO, Parisien M, Murphy LC, Watson PH: Influence of evolution in tumor biobanking on the interpretation of translational research. Cancer Epidemiol Biomarkers Prev. 2008; 17: 3344-50.

8. Chu TY, Hwang KS, Yu MH, Lee HS, Lai HC, Liu JY: A research-based tumor tissue bank of gynecologic oncology: characteristics of nucleic acids extracted from normal and tumor tissues from different sites. Int J Gynecol Cancer. 2002; 12: 171-6.

9. Balleine RL, Humphrey KE, Clarke CL: Tumour banks: providing human tissue for cancer research. Med J Aust. 2001; 175: 293-4.

10. Qualman SJ, Bowen J, Brewer-Swartz S, France M: The role of tumor banking and related informatics in molecular research. In: Ladanyi M, Gerald W (ed.), Expression profiling of human tumors: diagnostic and research applications. Totowa, NJ, Humana Press. 2003; pp. 103-17.

11. Brasil: Ministério da Saúde. Conselho Nacional de Saúde. [Internet] Resolução 196, de 10 de outubro de 1996. Diretrizes e Normas Regulamentadoras de Pesquisas envolvendo Seres Humanos. Brasília, DF. 1996. [cited jan. 2009]. Available from: http://e-legis. anvisa.gov.br/leisref/public/showAct.php?id=663

12. Brasil: Ministério da Saúde. Conselho Nacional de Saúde. [Internet] Resolução 347, de 13 de janeiro de 2005. Diretrizes e Normas Regulamentadoras de Pesquisas envolvendo Seres Humanos. Brasília, DF. 2005. [cited jan. 2009]. Available from: http://e-legis. anvisa.gov.br/leisref/public/showAct.php?id=18545

13. Sastre-Garau X: Cryopreserved tumor bank in the Pathology laboratory. Ann Pathol. 1995; 15: 233-4.

14. Adam D: Online tumour bank aims to offer ready route to tissues. Nature. 2002; 416: 464.

\section{Accepted after revision: January 21, 2010}

\section{Correspondence address:}

Dr. Marcos Francisco Dall'Oglio

Fundação Faculdade de Medicina

Av. Dr. Arnaldo 455, $2^{\circ}$ andar, sala 2141

São Paulo, SP, 01246-903, Brazil

E-mail: sasareis@gmail.com 


\section{EDITORIAL COMMENT}

That paper of Reis and co-workers is of great importance in the field of research since that will allow studies on a very well organized source of human materials kept in very good conditions. It is very important to save a lot of tissues (together with blood) and for many years. Thus, in order to avoid any problems and to meet scientists requirements for research project it is necessary to save duplicates / triplicates of tissues in at least two different places (not necessary in the same city). It is well known that saving tissues in only one $-80^{\circ} \mathrm{C}$ freeze is dangerous and it is better to have different banks in order to avoid any problems of safety (in case of electric power defect) and security. I would suggest also to have a website in order to inform people in your country about the relevance of that bank and thus organize meeting for future scientific projects in that area. What is also important to consider is the cost of keeping these samples for many years with highly specialized apparatus as well as technicians who must be aware of these conditions.

Dr. Serge Carreau Full-Professor University of Caen Basse-Normandie Biochemistry-IBFA Caen, France E-mail: serge.carreau@unicaen.fr 